\title{
QUALIDADE DE VIDA NO TRABALHO: CONTROLE E ESCONDIMENTO DO MAL-ESTAR DO TRABALHADOR
}

\author{
QUALITY OF WORK LIFE: CONTROL AND CONCEALMENT OF WORKER DISCONTENT
}

José Newton Garcia de Araújo ${ }^{1}$

Resumo Este texto tenta fazer eco à desconstrução dos programas de QVT, na ótica do artigo da professora Valquíria Padilha. O ponto de partida são as considerações de Castoriadis (1997), relativas à 'racionalidade' do capitalismo que, fundada na conformidade entre meios e fins, não se interroga sobre a própria racionalidade desses fins, supostamente inquestionáveis. Relembra-se também aqui a atualidade das análises de Marx sobre o modo de produção capitalista e seu sistema de trocas, fundado na mais-valia e que faz da alienação a essência do trabalho. Tal modo de produção continua sendo uma fonte permanente de acidentes, doenças e mortes no trabalho, fazendo milhões de vítimas, anualmente, em todo o planeta. As relações entre capital e trabalho se traduzem em um conflito inconciliável, que os ideólogos da gestão de recursos humanos tentam, no entanto, 'desconhecer' ou ocultar. As sucessivas inovações tecnológicas estão orientadas, segundo Castoriadis, para a redução e posterior eliminação do homem, nos processos de produção, embora isso só seja parcialmente possível. Assim sendo, a 'racionalidade' da gestão dos recursos humanos deve recorrer a sucessivas estratégias de manipulação-sedução do trabalhador, através dos recorrentes modismos gerenciais, entre os quais se inserem os programas de QVT.

Palavras-chave capitalismo; racionalidade; adoecimento no trabalho; recursos humanos; QVT.
Abstract This text tries to echo the deconstruction of the programs of Quality of work life (QWL), from the perspective of the article by Valkyrie Padilha. We start with Castoriadis' (1997) considerations on the 'rationality' of capitalism which, based on the conformity between means and ends, does not question itself about the very rationale of these supposedly unquestionable ends. It also highlights the currentness of Marx's analyses on the capitalist mode of production and its exchange system, based on surplus value and that turns alienation into the essence of work. This mode of production remains a constant source of accidents, illnesses and deaths at work, resulting in millions of victims each year across the globe. Relations between capital and labor are revealed as an irreconcilable conflict, however, the ideologists of the human resource management attempt to 'ignore' or hide it. Successive technological innovations are targeted, according to Castoriadis, towards the reduction and eventually the elimination of man, in the processes of production, although this is only partially possible. Thus, the 'rationality' of human resources management must resort to successive strategies of manipulation-seduction of the worker, through the recurring management fads, including QWL programs.

Keywords capitalism; rationality; illness at work; human resources; QVT. 
Além de agradecer ao honroso convite da coordenação editorial desta revista para participar da seção Debate, com base no artigo da professora Valquíria Padilha, devo confessar que tive, inicialmente, uma espécie de conforto, pelo fato de me identificar com as teses essenciais do texto. Mas logo em seguida o desconforto se anunciou, pois corria - e ainda corro - o risco da mesmice, ao simplesmente fazer eco às colocações da autora. De fato, o que escrevo aqui é uma espécie de reação primeira, gerada pela instigante leitura das ideias defendidas pela professora Valquíria a respeito dos programas de Qualidade de Vida no Trabalho (QVT). Limitei-me, pois, a desfiar um fio de reflexões que se sucederam, a partir da leitura do texto A 'racionalidade' do capitalismo, de Castoriadis (1997).

Julgo também pertinente assinalar que, ao partilhar da desconstrução dos princípios da QVT, caracterizados como válvulas de escape ou “analgésico que ameniza o efeito sem se preocupar em atacar as causas" (Padilha, 2009, p. 556), também partilho da aparente contradição assumida pela professora Valquíria, ao afirmar que "desenvolver políticas de QVT é melhor do que não fazê-lo". Entendo que buscar a melhoria de vida do trabalhador não significa concordar com o modo de produção capitalista, com o perverso sistema de trocas fundado na mais-valia. Por outro lado, acho inapropriado rotular tais melhorias de 'humanização' do trabalho. Mais inapropriado ainda seria admitir que elas se dão "em nome de uma 'humanização do capital"” (Padilha, 2009, p. 558). Lembremos que, se 'humanização' e 'humanismo' são vocábulos que não têm lugar no dicionário do capital, embora eles sejam objeto de uma utilização espúria pelos ideólogos do capitalismo, trata-se de um 'humanismo' contaminado, dos pontos de vista teórico, ético e político.

Outra observação: as antigas e atuais estratégias de 'gestão de pessoas', entre as quais estaria a QVT, nunca visaram promover a saúde do trabalhador, em seu sentido pleno. Simplesmente porque isso é impossível, sem a "democratização das relações sociais nos locais de trabalho" (Padilha, 2009, p. 559). As relações entre capital e trabalho são fundadas num conflito inconciliável. Por isso, é inerente ao papel dos gestores do capital impedir a autonomia e a emancipação do trabalhador. Caso contrário, estaríamos falando de outro modo de produção, de outro sistema de trocas, do qual a alienação ou a mais-valia seriam excluídas.

É neste sentido que retomo o fio das considerações relativas ao artigo da professora Valquíria, tendo como ponto de partida o citado texto de Castoriadis (1997).

Segundo este autor, o capitalismo é o primeiro regime social que produz uma ideologia que o afirma como 'racional'. Outros regimes sociais tinham uma legitimação mítica, religiosa ou tradicional. Mas de qual racionalidade se trata, em qual critério ela se sustenta? Seria a conformidade entre a operação e sua finalidade, ou seja, entre os meios e os fins. No entanto, nada se pergunta sobre a racionalidade desses fins. Esta só se refere aos meios, sendo os fins supostamente admitidos ou incontestáveis. Trata-se, pois, da racionalidade que 
Max Weber chamou de instrumental. Castoriadis (1997) comenta, por exemplo, que a escolha da bomba $\mathrm{H}$ para exterminar milhões de pessoas é uma escolha racional que permite a eficácia máxima para se atingir essa finalidade. E aqui já aparece a armadilha discursiva da ideologia capitalista

(...) que pretende em seus momentos mais filantrópicos, afirmar um fim da 'racionalidade', que seria o 'bem-estar'. Mas sua especificidade está naquilo que ela identifica esse bem-estar com um máximo - ou um ótimo - econômico (...) assim, direta ou indiretamente, a racionalidade é reduzida à racionalidade econômica, definida de maneira puramente quantitativa, como maximização/minimização maximização de um produto e minimização dos custos. (Castoriadis, 1997, p. 32).

Mas é essencial que tais armadilhas discursivas sejam negadas, enquanto tais. Os ideólogos 'humanistas' do capital e os estrategistas de recursos humanos diriam, certamente, que os escritos de Marx, colocando às claras a alienação do trabalhador e sua aniquilação física e mental, são coisas do passado, dos meados do século XIX. Lembremos algumas conhecidas passagens dos Manuscritos econômico-filosóficos (Marx, 1993) confrontando-as com o que se passa no mundo do trabalho, nos dias atuais. A respeito da alienação, vejamos a seguinte citação do filósofo:

o trabalhador coloca a sua vida no objeto; mas agora ela não pertence mais a ele, mas sim ao objeto. Portanto, quão maior esta atividade, tanto mais o trabalhador é sem-objeto. Ele não é o que é o produto do seu trabalho. Portanto, quão maior este produto, tanto menos ele mesmo é. A exteriorização do trabalhador em seu produto tem o significado não só de que o seu trabalho se torna um objeto, uma existência exterior, mas também que ela existe fora dele, independente de e alheia a ele, tornando-se um poder autônomo frente a ele, //o significado// de que a vida que ele conferiu ao objeto se lhe defronta inimiga e alheia (Marx apud Fernandes, 1983, p. 151).2

Em sua crítica aos economistas que naturalizavam as relações de trabalho inerentes ao modo de produção capitalista, atribuindo ao trabalhador o lugar de mero 'recurso', tanto quanto os atuais ideólogos do capital que inspiram as políticas de recursos humanos nas empresas, Marx já escrevia:

a partir da Economia Política mesma (...) mostramos que o trabalhador decai a uma mercadoria e à mais miserável mercadoria, que a miséria do trabalhador está na razão inversa do poder e da magnitude da sua produção, que o resultado necessário da concorrência é a acumulação do capital em poucas mãos (...) (Marx apud Fernandes, 1983, p. 147).

Imagino que os otimistas defensores da QVT também dirão que Marx deve mesmo ser jogado no lixo da história, quando ele afirma que 
(...) a alienação do trabalhador em seu objeto se expressa de maneira que quanto mais o trabalhador produz, tanto menos tem para consumir, que quanto mais valores cria, tanto mais se torna sem valor e sem dignidade, que quanto melhor formado o seu produto, tanto mais deformado o trabalhador, que quanto mais civilizado o seu objeto, tanto mais bárbaro o trabalhador, que quanto mais poderoso o trabalho, tanto mais impotente se torna o trabalhador, que quanto mais rico de espírito o trabalho, tanto mais o trabalhador se torna pobre de espírito e servo da natureza. (Marx apud Fernandes, 1983, p. 152).

Mais irritados ficariam ainda os aguerridos defensores da QVT (ou talvez optassem pela zombaria e menosprezo) diante de um Marx que desconhecia os avanços da 'humanização' dos sistemas de produção, quando afirmava que a economia política oculta a alienação na essência do trabalho:

O trabalho produz maravilhas para os ricos, mas produz desnudez para o trabalhador. Produz palácios, mas cavernas para o trabalhador. Produz beleza, mas mutilação para o trabalhador. Substitui o trabalho por máquinas, mas joga uma parte dos trabalhadores de volta a um trabalho bárbaro e faz da outra parte máquinas. Produz espírito, mas produz idiotia, cretinismo para o trabalhador. (Marx apud Fernandes, 1983, p. 152). ${ }^{3}$

Mas será que estas afirmações de Marx estão mesmo ultrapassadas? Referindo-se a uma fase recente do capitalismo neoliberal, no final do século XX, marcadas por um recuo do desemprego nos EUA e na Inglaterra, Castoriadis (1997) afirma que tal fenômeno não significou um ganho social para as classes trabalhadoras. Ao contrário, o aumento de empregos se deu ao preço da proliferação de trabalhos em tempo parcial ou mal remunerados, da estagnação ou redução dos salários reais, paralelamente ao aumento contínuo dos lucros das empresas e da renda das classes ricas, o que lembra o retorno ainda maior à barbárie do capitalismo:

Assistimos a uma fase de transição brutal, selvagem, em escala muito mais vasta e em um lapso de tempo muito mais curto que nas outras fases de transição da história do capitalismo (...) as empresas transnacionais, a especulação financeira e mesmo as máfias, no sentido estrito do termo, se espalharam pelo planeta, guiadas unicamente pela visão a curto prazo de seus lucros (Castoriadis, 1997, p. 51).

Desconhecendo tal afirmação, o discurso empresarial que alimenta as práticas hegemônicas de $\mathrm{RH}$, entre as quais a QVT, também desconhece (ou oculta) que os ambientes de trabalho são uma fonte permanente de acidentes, doenças e mortes, fazendo milhões de vítimas, anualmente, em todo o planeta. Se abrirmos os manuais, livros e cartilhas dos 'gurus' da gestão empresarial, 
certamente não veremos nenhuma referência aos 160 milhões de novos casos, no mundo, de acidentes ou doenças relacionadas ao trabalho, nem aos seis mil casos de morte diária, em consequência desses acidentes, em 2008 (Rede Brasil Atual, 2009). Nem saberemos que, no Brasil, em 2007, ocorreram 653 mil acidentes de trabalho, 27,5\% a mais que em 2006. E que, deste total, 8.504 trabalhadores tornaram-se incapacitados permanentes, outros 2.804 morreram, em decorrência dos mesmos acidentes de trabalho (Ministério da Previdência Social, 2009). Note-se que tais números são subnotificados, pois se referem apenas aos acidentes e mortes oficialmente registrados. Destes números não constam os ocorridos nos setores público e informal, além daqueles para os quais o setor privado não emite a CAT (comunicação de acidente de trabalho) à Seguridade Social. Sabemos que muitas empresas terceirizam ou migram suas atividades de risco para a informalidade, a fim de divulgarem o 'zero acidente', em seus ambientes de trabalho, a fim de se afirmarem como 'socialmente responsáveis'. Sabemos também que muitos trabalhadores escondem seu adoecimento para não serem demitidos, o que ajuda a cronificar a subnotificação dos acidentes.

É importante lembrar que o conceito de acidente de trabalho (AT) não remete só a eventos súbitos que lesam o trabalhador. A lei n. ${ }^{\circ} 6.367$, de 19 de outubro de 1976, em seu art. $2^{\circ}$, considera como acidente do trabalho o evento que "ocorrer pelo exercício do trabalho a serviço da empresa, provocando lesão corporal ou perturbação funcional que cause a morte, ou perda, ou redução, permanente ou temporária, da capacidade para o trabalho" (Brasil, 1976).

Aqui se incluem as chamadas doenças profissionais ou ocupacionais, que se desenvolvem lentamente, em função das condições e da organização do trabalho. A noção de AT contempla, pois, todos os tipos de "lesão, doença, transtorno de saúde, distúrbio, disfunção ou síndrome de evolução aguda, subaguda ou crônica, de natureza clínica ou subclínica, inclusive morte, independentemente do tempo de latência" (Equipe Guia Trabalhista, 2009).

Voltemos ainda a Marx para lembrar que, em função da alienação, da exteriorização ou 'estranheza' da atividade, os danos causados ao trabalhador não se restringem às doenças ou acidentes 'visíveis', pois atingem corpo e mente, o sofrimento é somático e psíquico.

Primeiro, que o trabalho é exterior ao trabalhador, ou seja, não pertence à sua essência, que portanto ele não se afirma, mas se nega em seu trabalho, que não se sente bem, mas infeliz, que não desenvolve energia mental e física livre, mas mortifica a sua physis e arruína a sua mente. Daí que o trabalhador só se sinta junto a si fora do trabalho e fora de si no trabalho. Sente-se em casa quando não trabalha e quando trabalha não se sente em casa (Marx apud Fernandes, 1983, p. 153).

Será que, através das novas tecnologias de gestão, os trabalhadores se sentem 'em casa'? Mas não seriam elas, como está apontado no texto da professora 
Valquíria, justamente a 'morada' da desregulamentação e perdas dos direitos trabalhistas, morada dos trabalhos temporários e informais, da terceirização, do aumento da jornada com acúmulo de funções, da maior exposição a fatores de riscos, do rebaixamento salarial, da instabilidade no emprego, enfim, da intensificação e da precarização do trabalho?

Este cenário aponta para uma mudança do perfil de adoecimentos, concomitante à mudança das tecnologias de produção e de gestão de recursos humanos. O que abala o sujeito não é apenas sua relação imediata com o trabalho, não apenas os agravos ao seu corpo. A instabilidade no emprego, o assédio moral que tende a tornar-se estrutural, inerente aos modelos de gestão, embora mesclados com as táticas de sedução inscritas no discurso empresarial, inclusive nas práticas de QVT, abalam especialmente a estrutura psíquica do trabalhador. Não é de se estranhar que, como afirma Guimarães (2009), 30\% da população trabalhadora, formalmente ativa, sofrem dos chamados Transtornos Mentais Menores (TMM), sendo que 5\% a $10 \%$ deste mesmo universo padecem de Transtornos Mentais Graves, deixando os sujeitos incapacitados para o trabalho. Assim, os transtornos mentais são responsáveis por cinco entre as dez principais causas de incapacitação para o trabalho. No Brasil, eles estão em terceiro lugar, entre as causas de concessão de benefícios previdenciários. No período de 1998-2002, de 18 milhões de pessoas com carteira assinada, 270.382 tiveram tais benefícios concedidos, devido a algum tipo de transtorno mental (Guimarães, 2009).

Se os dados acima, referentes a mortes, acidentes e agravos à saúde física e mental do trabalhador, podem ser considerados excessivos, caberia perguntarmos: excessivos para quem? Certamente não para os gestores dos processos de produção, no sistema capitalista, eles mesmos presos a tais modos de produção, tendo como fiéis coadjuvantes os profissionais de RH.

Não se trata aqui de carimbar esses gestores como vilões, de demonizá-los, mas de termos claro que, antes deles, os processos de produção, a quem eles servem, é que são estruturalmente lesivos aos trabalhadores. Assim, não seria estranho afirmar que os acidentes, mortes e todas as formas de adoecimento no trabalho são 'programadas' ou 'projetadas'. Exagero? Quando Marx dizia que o trabalho mortifica a physis e arruína a mente do trabalhador, decaído à condição da mais miserável mercadoria, ele via a gênese das doenças laborais já presente na divisão manufatureira do trabalho. ${ }^{4} \mathrm{Na}$ análise deste processo, ele deixou claro que

Certa deformação física e espiritual é inseparável mesmo da divisão do trabalho (...) o período manufatureiro leva muito mais longe essa divisão social dos ramos de trabalho e (...) alcança o indivíduo em suas raízes vitais, é ele o primeiro a fornecer o material e dar o impulso para a patologia industrial (Marx, 1983, p. 285). 
A respeito dessa afirmação de Marx, Lima acrescenta:

É interessante notar que, logo em seguida, Marx faz referência à obra clássica de Ramazzini, datada de 1713, acrescentando que "o período da grande indústria ampliou de muito, naturalmente, seu catálogo de doenças dos trabalhadores" (Marx, 1983, p. 285). O que importa aqui ressaltar é a afirmação subjacente do caráter histórico-social das doenças dos trabalhadores, variáveis segundo os diferentes 'períodos' da produção e também determinadas pela divisão social do trabalho (Lima, 1998, p. 254).

Não se trata, pois, de dizer que 'alguém programou' as mortes ou doenças do trabalho, mas que estes 'acidentes' ocorrem, inexoravelmente. Certas doenças do trabalho - as LER/Dort, os 'transtornos mentais menores' etc. são epidêmicas, no atual panorama do mundo do trabalho. Os dados estatísticos o evidenciam. Estamos diante de questões ergonômicas, sociológicas e antropológicas que resistem às enganosas 'soluções' psicologizantes ou às inovações da 'gestão de pessoas'.

Isso ainda implica que a noção de 'acidente' não é sinônimo de acaso, de algo imprevisto ou inesperado. $\mathrm{O}$ acidente decorre das condições e da organização do trabalho. Se, de um lado, ele não atinge todos os trabalhadores, num determinado ambiente de trabalho, isso não significa que os 'acidentados' são responsáveis pelo agravo, nem que eles foram mal selecionados, segundo a máxima taylorista 'o homem certo para o lugar certo'. Não é o descuido ou desatenção do trabalhador que o lesa, como afirmam alguns gestores e responsáveis internos pela segurança e saúde do trabalhador.

O que está em jogo aqui não é a incúria do trabalhador nem o eventual estilo autoritário de liderança, nem a presença ou ausência da QVT, da Reengenharia ou da Qualidade Total, nem o uso obrigatório dos EPI's (equipamentos de proteção individual), nem as novas tecnologias de produção ou quaisquer tentativas de 'humanização' do trabalho. Pois tudo isso está a serviço das condições de dominação do capital sobre o trabalho. As inovações técnicas não passariam, segundo Marx, de uma forma de exploração civilizada e refinada:

Ainda que apareça, por um lado, como progresso histórico e momento necessário de desenvolvimento de processo de formação econômica da sociedade, por outro, ela surge como um meio de exploração civilizada e refinada (Marx, 1983, p. 286).

Estas considerações nos levam de volta à argumentação de Castoriadis (1997), relativa à racionalidade do capitalismo. Como vimos, ela visa essencialmente a aumentar a produção e diminuir os custos. O autor mais uma vez pergunta: de quais custos trata essa racionalidade, onde incidem seus cálculos? Para ele, a 'razão' do capital não se interroga, por exemplo, sobre os custos relativos à 
destruição do meio ambiente, à homogeneização da vida humana, à feiúra das cidades, à vitória da irresponsabilidade e do cinismo. Assim, a 'significação imaginária social nuclear do capitalismo', impulsionada para uma busca ilimitada do 'controle racional' e marcada pelos avanços técnicos ou pela tecnociência, tem um traço particular: "ela é, de maneira predominante, orientada para a redução, depois para a eliminação do papel do homem na produção. Isto se compreende, pois o homem é o elemento mais difícil de se controlar" (Castoriadis, 1997, p. 38).

Esta última afirmação do autor remete a duas questões: de um lado, seria excelente para o capital o desaparecimento total do homem, nos processos de trabalho, uma vez que este 'recurso' pensa, sente, sofre, desliza entre a submissão e a crítica, adoece, faz greves etc. Os demais recursos, as máquinas mecânicas ou as inteligentes, além de substituir a força de trabalho de milhares de humanos, não têm outro tempo ou espaço, enfim, outra vida fora do trabalho. No entanto, de outro lado, o capital ainda precisa do trabalho vivo. Segundo Lima (1998), a substituição do homem pela máquina depende de dois requisitos, um técnico e outro econômico: de um lado, a máquina deve ser mais eficiente que o trabalho humano, de outro, ela deve obter resultados mais econômicos que o trabalho vivo (do homem). Isso "implica em cálculos econômicos dependentes de condições histórico-sociais e mediados pelo mercado" (Lima, 1998, p. 244). Além disso, continua o autor, certas atividades que dependem de habilidades manuais e mentais ainda não podem, no atual estágio tecnológico, ser realizadas pelas máquinas. "Os processos de trabalho reais são, de fato, mistos, mesmo sistemas altamente automatizados dependem ainda de controles cognitivos e de intervenções manuais realizadas pelos trabalhadores que operam esses sistemas" (Lima, 1988, p. 245).

O que resta então, já que é impossível eliminar o 'fator humano', nos sistemas de produção, senão o controle e a docilização dessa incômoda 'força de trabalho', de modo que ela possa servir ao capital, segundo o critério da maximização de seus interesses? Resta a gestão pragmática desses recursos, em cujos desdobramentos figura o "teatro da humanização do trabalho", expressão à qual a professora Valquíria se referiu, citando um texto no qual eu tentei mostrar como, ao longo da História, o capital insiste, a um só tempo, em submeter e seduzir o trabalhador (Araújo, 2008).

Neste texto, tentei argumentar que mesmo os gestores pré-capitalistas já antecipavam práticas que a psicologia industrial viria posteriormente aconselhar aos empresários, especialmente a partir do movimento das 'relações humanas'. Em outras palavras, a fim de explorar e espoliar eficazmente o trabalhador, é preciso inventar relações aparentemente amistosas com ele. Relembremos, em breves alusões, algumas dessas práticas. No Brasil-colônia, Rugendas (1949) narra os 'mimos' dos senhores (clérigos e civis) aos escravos, a fim de "tornar a escravidão suportável, tanto quanto possa sê-lo uma condição tão contrária à natureza" (Rugendas, 1949, p. 169). Bosi (1992) evoca, com rara maestria, a 
figura do jesuíta Antonil, analisado como "nosso primeiro economista" ou "um mentor da psicologia industrial do seu tempo", mas (o que era coerente com sua ideologia psicogerencial) cuja "consciência moral já está inteiramente dobrada às razões do mercantilismo colonial" (Bosi, 1992, p. 154). Neste mesmo cenário, o índio, anteriormente glorificado como 'bom selvagem' pelo colonizador europeu, é depois adjetivado como traiçoeiro, "sem Deus, sem Rei, sem Lei", preguiçoso e indolente, enfim, "não-civilizado", "pouco trabalhador", justamente porque não se submetia ao colonizador, ou seja, cometia o absurdo de só cultivar o necessário para a sua nutrição (Le Ven, 2001).

Nos meados do século XVII, a figura de Colbert, evocada por Jacob (1995), é descrita como um 'homem de poder' que, apesar de afirmar a indolência dos trabalhadores, já prenunciava os passos da 'psicologia da administração', ao sugerir não só que "os homens se sentem bem, desde que queiram trabalhar", mas que, para torná-los mais lucrativos, era preciso, sobretudo, "excitar ao trabalho" (Jacob, 1992, p. 55). Desse modo, Colbert já ensaiava os primeiros passos das práticas da 'motivação'.

Mas quem mesmo deu impulso ao teatro da humanização do trabalho, já no século XX, foi o conservador Elton Mayo. Suas descobertas, cujo pano de fundo era uma psicologia adaptativa e funcionalista, da qual nasceu a escola de 'relações humanas', foram um prolongamento sofisticado do sistema taylorista. Com as propostas de valorização do homem no trabalho, ele empolgou os círculos empresariais, dando-lhes a chave para se conseguir a adesão e a submissão do trabalhador: a sua 'valorização', desde que, bem entendido, todos os trabalhadores só cooperassem com a empresa, nunca contestassem. A oposição de Mayo às lideranças sindicais era ostensiva. Segundo Gabor (2001, p. 116), ele "continuou resistindo à necessidade dos sindicatos, afirmando que empregadores esclarecidos, ao se antecipar à sindicalização, a tornariam obsoleta". Ao descobrir a organização grupal e informal, bem como a solidariedade e a cooperação entre os trabalhadores, Mayo descobriu, mas em seguida encobriu que tal cooperação não era a reconciliação capital-trabalho, mas uma forma de agrupamento ligado à resistência e à luta (Enriquez, 1987).

Sem nos determos em todos os momentos históricos ou nos recorrentes modismos dos ideólogos do capital, que inspiram todas as "inovações" de gestão de recursos humanos, lembremos as recentes investidas da chamada gestão estratégica. Segundo Enriquez (1997), as empresas convidam o trabalhador à participação, a se sacrificar inteiramente à sua 'boa causa'. Elas pregam a inovação, mas uma inovação vigiada, uma participação e uma liberdade controladas, elas querem que o trabalho, baseado na cooperação imposta, dê sentido à vida do trabalhador. Assim, os indivíduos são apanhados na armadilha de seu desejo de reconhecimento e se entregam de corpo e alma ao trabalho, colocando a serviço da empresa seu potencial físico, intelectual e afetivo... até o dia em que são dispensados, por não serem mais considerados 'úteis' à empresa. Segundo 
este autor, o capitalismo fez da empresa uma instituição sagrada, um objeto idealizado, até levando os sujeitos a substituir seu ideal do eu pessoal pelo ideal do eu da organização. Assim, a gestão estratégica, fingindo respeitar o trabalhador, aliena-o mais ainda (Enriquez, 1996).

\section{Considerações finais}

Ao longo deste debate, como disse no começo do texto, talvez eu tenha apenas reforçado as teses da professora Valquíria, no sentido de questionar as práticas da QVT. Afinal, a tarefa de debater um artigo é diferente daquela de escrever um 'texto próprio', sendo o ofício do debatedor um exercício de 'correr atrás' do tema original, através de considerações que contestem ou corroborem as hipóteses de trabalho levantadas pelo autor, no caso, a professora Valquíria.

Vou terminar aqui com uma pergunta para a qual não tenho elementos de resposta. Trata-se do seguinte: em qual lugar se colocam alguns autores de 'receituários' da QVT, tais como Walton? Ou melhor: qual a finalidade dessa 'receita'? Será que algum trabalhador acredita nesse 'Papai Noel'? Será que algum gestor de RH ousaria colocá-la em prática? Ou será que, simplesmente, 'de tanto repetirmos algumas inverdades, elas acabam se tornando verdades'?

Com efeito, o 'Quadro l', mostrando as categorias de QVT levantadas por Walton, não passam de um rol de itens bem-intencionados e vazios, pois negados, via de regra, pela realidade cotidiana do trabalho, nos mais diversos modelos de empresas, sejam elas públicas ou privadas, nacionais ou multinacionais, grandes, médias ou microempresas. Este quadro aponta, com efeito, para um paraíso laboral, no qual constam, entre outros ítens: salários dignos, ausência de condições laborais ameaçadoras, oportunidades imediatas de desenvolvimento e uso das capacidades, garantia do emprego, espaço de estruturação da identidade pessoal e integração social, direitos trabalhistas garantidos, além de outros.

Se as práticas de QVT podem levar a vivências passageiras de bemestar no trabalho, conforme consta no Quadro 2, proposto por Ferreira, longe estamos do exercício da "cidadania organizacional nos ambientes de trabalho" (Padilha, 2009, p. ...), do reconhecimento institucional e coletivo do trabalhador, da possibilidade de crescimento profissional e de respeito às características individuais.

As 'receitas' que apontam para o equilíbrio entre os objetivos pessoais e os objetivos da organização (Padilha, 2009) 'desconhecem' a realidade inexorável do conflito capital versus trabalho. Assim, os arremedos de 'humanização' dos ambientes laborais, longe de superar as contradições inerentes ao modo de produção capitalista, constituem, eles próprios, uma contradição: conciliar o inconciliável. 
Segundo Araújo (2009), alguns formuladores da 'gestão estratégica', insinuando que o profissional de RH deva ser um defensor dos funcionários, deixam bem claros os conteúdos perversos dessa 'conciliação'. A autora analisa, por exemplo, alguns pressupostos de Ulrich (2000), para quem o papel do RH nada mais é que "planejamento por resultado":

Diante da exigência de realizar mais [lucros] com menos [trabalhadores], o RH deve verificar se os funcionários estão totalmente disponíveis para a empresa, tendo a incumbência de comprometê-los, fazer com que "se sintam obrigados com a empresa e colaborem em tudo" (Ulrich, 2000, p. 43). Deverá ensinar aos gerentes como 'operar sobre o moral dos funcionários' (Ulrich, 2000, p. 44) (...) deve instaurar a cultura da urgência e ainda gerar entusiasmo nas pessoas (Araújo, 2009, p. 69).

Digamos que Ulrich é mais transparente que Walton. Ele deixa clara a finalidade 'humanista' do RH, através das práticas de QVT e similares. Trassati (2005, apud Araújo, 2009) nos oferece uma síntese da 'missão' do profissional de RH:

Neste cenário, surgiu a figura de uma área de recursos humanos importante. Coube a ela a elaboração de planos, táticas e ações contingenciais 'contra' os sindicatos (...) o objetivo maior era manter a empresa trabalhando sem greve, quase a qualquer custo (...) 'Recursos humanos' tinha a função de 'proteger' a empresa, 'fazer a cabeça dos funcionários', permitindo que esses 'vestissem a camisa da empresa'. (Trassati, 2005, apud Araújo, 2009, p. 62-63).

Eugène Enriquez nos tem mostrado, em diversos textos críticos, como a sutileza das empresas, em seu objetivo de administrar não somente a força de trabalho, mas sobretudo a afetividade dos trabalhadores, faz com que estes lhes dediquem todas as suas habilidades, suas capacidades intelectuais, sua libido. No entanto, este autor acrescenta que, "na hora atual, as empresas estratégicas não podem levar a seus trabalhadores senão um 'desgaste mental' provocado pela carga psíquica desmesurada investida na manutenção da função ocupada (...)" (Enriquez, 1997a, p. 72).

Estas considerações reforçam as hipóteses de que os programas de qualidade de vida no trabalho, mesmo que ajuem a tornar menos 'selvagem' a exploração do trabalhador, apenas reproduzem o 'teatro humanista' de conciliar o inconciliável conflito entre capital e trabalho. 


\section{Notas}

1 Professor do Instituto de Psicologia e do Programa de Pós-Graduação em Psicologia da Pontifícia Universidade Católica de Minas Gerais (PUC Minas), Belo Horizonte, Minas Gerais, Brasil. Doutor em Psicologia pela Universidade de Paris 7. <jinga@uol.com.br>. Correspondência: PUC Minas, Avenida Itaú, 525, Prédio Redentoristas, $1^{\circ}$ subsolo, sala 105, Bairro Dom Cabral, Belo Horizonte, Minas Gerais, Brasil, CEP 30535-012.

2 Tomo aqui as citações extraídas de textos de Marx comentados por Florestan Fernandes (1983).

3 Lembremos que 'idiotia' se refere a um acentuado atraso intelectual ou um nível mental inferior, muitas vezes acompanhado de malformações físicas; e o 'cretinismo' seria um estado mórbido produzido pela ausência ou insuficiência da glândula tireóide - prejuízo orgânico e psíquico, ou seja, formas de acometimento orgânico e psíquico, que podem remeter, como paradigma, às demais 'deformações' físicas e psíquicas provocadas pelo excesso de exploração do sujeito humano no trabalho.

4 Estas considerações estão desenvolvidas de maneira muito mais extensa e argumentada no artigo "A organização da produção e a produção da L.E.R.", de Francisco de Paula Antunes Lima, no livro L.E.R.: dimensões ergonômicas e psicossociais, organizado por Lima, M. E. A., Araújo, J. N. G. e Lima, F. P. A. Belo Horizonte: Health, p. 237-263, 1998.

\section{Referências}

ARAÚJO, José N. G. Entre servidão e sedução do trabalhador. In: MENDES, Ana Magnólia (Org.). Trabalho e saúde: o sujeito entre servidão e emancipação. Curitiba: Juruá. 2008.

ARAÚJO, Terezinha M. Recursos humanos, demasiadamente humanos: uma experiência revisitada. Dissertação (Mestrado em Psicologia) - Programa de Pós-Graduação em Psicologia. Belo Horizonte: PUC Minas, 2009.

BOSI, Alfredo. A dialética da colonização. São Paulo: Companhia das Letras, 1992.

BRASIL. Lei n. ${ }^{\circ}$ 6.367, de 19 de outubro de 1976. Dispõe sobre o seguro de acidentes do trabalho a cargo do INPS. Brasília, DF: Diário Oficial da União, 19 out. 1976.
CASTORIADIS, Cornelius. La «rationalité» du capitalisme. Revue Internationale de Psychosociologie, v.. 4, n. 8, p. 31-51, 1997.

ENRIQUEZ, Eugène. Rapport au travail et pratique psychosociologique. Connexions, n. 24, p. 85-108, 1987.

. Prefácio. In: DAVEL, Eduardo; VASCONCELOS, João G. (Orgs.). 'Recursos' humanos e subjetividade. Petrópolis: Vozes, 1996, p. 7-22.

O indivíduo preso na armadilha da estrutura estratégica. RAE - Revista de Administração de Empresas, v. 37, n. 1, p. 18-29, 1997.

Les jeux du pouvoir et du désir dans l'entreprise. Paris: Desclée de Brouwer, 1997a. 
EQUIPE GUIA TRABALHISTA, 2009. Disponível em: <www.guiatrabalhista.com.br/ noticias/trabalhista210306.htm > . Acesso em: 2 jun. 2009

FERNANDES, Florestan (org.). Marx-Engels: história. São Paulo: Editora Ática, 1983.

GABOR, Andrea. Os filósofos do capitalismo. Rio de Janeiro: Campus, 2001.

GUimARÃES, Liliana A. M. Atualizações em saúde mental do trabalhador. Disponível em: <www.saude.df.gov.br/sites/100/163/ 00006126.ppt>. Acesso em: 2 jun. 2009.

LE VEN, Michel. Trabalhadores do Brasil: história e memória. In: Araújo, José N. G. \& Carreteiro, Teresa C. (Orgs.). Cenários sociais e abordagem clínica. São Paulo: Escuta / Belo Horizonte: Autêntica, 2001.

MARX, K. O capital. vols. I/1 e I/2. São Paulo: Abril Cultural, 1983.

MARX, Karl. Manuscritos econômico-filosóficos. Lisboa: Edições 70, 1993.
PADILHA, Valquíria. Qualidade de Vida no Trabalho num cenário de precarização: a panaceia delirante. Revista Trabalho, Educação e Saúde, v. 7, n. 3, p. 549-563, nov. 2009/ mar. 2010.

REDE BRASIL ATUAL. Disponível em: < www. redebrasilatual.com.br/temas/trabalho/acidentesde-trabalho-numeros-que-impressionam $>$. Acesso: em 4 jul. 2009.

RUGENDAS, Johann. M. Viagem pitoresca através do Brasil. São Paulo: Martins, 1949.

TRASATTI, Sidney R. Treinamento de competências funcionais: moldando o futuro organizacional pelas pessoas. In: NERI, Aguinaldo (Org.). Gestão de RH por competências e a empregabilidade. São Paulo: Papirus, p. 2849, 2005.

ULRICH, Dave. Os campeões de recursos humanos: inovando para obter os melhores resultados. São Paulo: Futura. 2000. 